\title{
How Do Women Decide? Accepting or Declining BRCA1/2 Testing in a Nationwide Clinical Sample in the United States
}

\author{
Pamela Sankar ${ }^{\mathrm{a}}$ Paul Root Wolpe ${ }^{\mathrm{a}}$ Nora L. Jones ${ }^{\mathrm{a}}$ Mildred Cho ${ }^{\mathrm{b}}$ \\ ${ }^{a}$ Center for Bioethics, University of Pennsylvania, Philadelphia, Pa., and ${ }^{b}$ Center for Biomedical Ethics, \\ Stanford University School of Medicine, Palo Alto, Calif., USA
}

\section{Key Words}

BRCA1/2 · Counseling • Decision-making • Genetic testing $\cdot$ Informed consent

\begin{abstract}
Objective: To examine the role of the practitioner, informed consent, and genetic counseling in genetic testing decisions and to assess their relative influence on women's decision to have clinical BRCA1/2 testing. Methods: Qualitative study using in-depth open-ended interviews with 68 women who had considered clinical BRCA1/2 testing. Results: Slightly less than half of the women who had considered BRCA $1 / 2$ testing were found to have had a clear and preexisting desire to test or not to test, irrespective of practitioner attitude or advice. Conclusion: The decision to accept or decline genetic testing is the result of a complex process that goes beyond interactions between health care providers and patients, indicating a caution against exclusive reliance on informed consent or counseling encounters.
\end{abstract}

Copyright (C) 2006 S. Karger AG, Basel

\section{Introduction}

The introduction of BRCA1 and BRCA2 (BRCA1/2) testing marked the first time a genetic test was made available for a relatively common adult-onset disease.
When the test first became available for clinical use in 1995, critics suggested that it was not yet ready for the general population because its utility had been demonstrated only on high-risk populations and because primary-care practitioners were ill prepared to counsel women about its use and to explain the implications of test results. Physician organizations, such as the American Society of Clinical Oncology (ASCO), proposed testing guidelines that stipulated that the test's 'potential medical, psychological, and other personal risks ... must be addressed in the context of informed consent for genetic testing' [1].

The strategy to protect patients from potential risks of uninformed testing through informed consent rests on a number of assumptions about the genetic test decisionmaking process, as well as the function of informed consent or genetic counseling within that process. These assumptions are largely untested. For example, the reliance on these processes presumes that the decision to accept or refuse genetic testing is substantially based on interactions between health care providers and patients, and on information exchanges that occur during such encounters, as well as on medical or medically related characteristics of the patient, such as hereditary breast cancer risk.

Two types of studies have explored factors around accepting or refusing genetic testing for hereditary breast and ovarian cancer and other late-onset conditions. One strategy has been to examine factors influencing deci-

\section{KARGER}

Fax +4161306 1234 E-Mail karger@karger.ch www.karger.com
(C) 2006 S. Karger AG, Basel

$1422-2795 / 06 / 0092-0078 \$ 23.50 / 0$

Accessible online at:

www.karger.com/cmg
Pamela Sankar, $\mathrm{PhD}$

Center for Bioethics, University of Pennsylvania

3401 Market Street, Suite 320

Philadelphia, PA 19104 (USA)

Tel. +1 215573 8105, Fax +1 215573 3036, E-Mail sankarp@mail.med.upenn.edu 
sion-making in hypothetical vignettes about genetic testing administered to women who were not in real life considering testing (and who may not even have had a history of cancer) [2-6]. For example, one study of primary-care patients found that $58 \%$ were interested in genetic testing for breast cancer if it was convenient and affordable; but interest was inversely associated with a family history of breast cancer and with increasing age $[2,5]$. However, a sample of women who had undergone mammography screening 12-14 months previously found no correlation of likelihood to test with either family history or age [5]. Such studies may not reflect actual clinical populations who are considering testing, or may not correctly mimic decision-making patterns or scenarios by such women.

The second type of study on BRCA $1 / 2$ testing uses existing research populations [7-9]. In most cases, these studies have drawn their subjects from women who are enrolled in BRCA1/2 clinical research, not from actual clinical populations. Women agreeing to participate in this type of research study typically undergo a standardized protocol of genetic counseling and an additional informed consent process related to the study itself. Studies of research-based testing have provided considerable insight into the kinds of concerns women bring to the BRCA $1 / 2$ testing decision and into the types of women likely to accept testing. However, the controlled conditions of these studies, as well as the process of decisionmaking about testing, may not reflect the real-life experience of seeking information and counseling for BRCA1/2 testing in clinical settings. In addition, both types of study designs generally share the presumptions about decision-making and informed consent described above. To examine the role of informed consent and genetic counseling in genetic testing decisions in actual decisionmaking conditions, outside of a research setting and defined counseling protocol, we conducted a retrospective interview study of 68 self-selected women who had considered clinical BRCA1/2 testing during 1998 and 1999.

\section{Subjects and Methods}

The relatively low rate of BRCA1/2 testing (estimated in one study at $31 \%$ among patients with a family history of hereditary breast or ovarian cancer) $[10,11]$ and the absence of any centralized means for identifying women who have considered testing in a clinical setting imposed an exploratory design on this research. We sought a sample that represented women who had declined and women who had accepted testing in typical health care delivery settings, and set primarily descriptive rather than hypothesis-testing goals. We requested data about the overall decision-making process, starting from the earliest point the subject could recall learning about the existence of BRCA1/2 testing, and extending over the course of visits to practitioners until the point subjects identified as ending their current interest, either by accepting or declining testing. This interest required reliance on post-decisional recall, which is known to affect explanation of pre-decisional considerations [12]. However, this method is appropriate for our objective to contextualize informed consent within the broad array of interactions with practitioners about testing, and our interview was structured to respond to this concern. Our research was approved by the University of Pennsylvania Institutional Review Board.

\section{Recruitment}

Through a mailed survey of physicians in the US, as part of a separate study [13], we determined a subset of practitioners who had discussed BRCA1/2 testing with at least one of his or her patients. Six thousand physicians, who were members of the American Medical Association, were systematically sampled from a list obtained from Medical Marketing Service (the company franchised to manage the Physicians List of the American Medical Association) from the following subspecialties: medical and clinical genetics, reproductive endocrinology, oncology, hematology/oncology, gynecology, surgery/surgical oncology, obstetrics, internal medicine, family practice, and general practice.

Of the responding practitioners, 1,018 answered that they had discussed BRCA $1 / 2$ testing with a patient in the previous 6 months. We contacted these practitioners by mail and asked if they would be willing to alert their patients to our study by providing them with a brief description of it, and a card that displayed the name of the study and a toll-free number they could call to get further information about our study. We chose to inform patients about our study indirectly, through their practitioners, and to allow patients to contact us, anonymously if they wished, in order to maximize privacy and confidentiality. Practitioners were directed to distribute cards only to patients who had considered testing to the point of engaging with practitioners in a specific discussion dedicated to reviewing the test's features and its suitability for their situation and to include those who had declined the test as well as those who had accepted it. Pilot interviews conducted in preparation for this study had made clear that while some women received extensive counseling, others received none, or had received counseling from physicians, nurses, or other health care professionals. We therefore did not use formal genetic counseling as a criterion for inclusion, and instead recruited women in a way that reflected the range of experiences they actually encountered in pursuing BRCA testing.

\section{Interviews}

The interview consisted of a set of closed-ended questions about demographic factors, such as age, education, and economic status, an 11-question test of genetic cancer knowledge, and an individual and family cancer history, specifying type of cancer, degree of relatedness, and age of onset for each relative. The cancer knowledge test consisted of 11 true/false questions that were developed and validated by the Cancer Genetics Consortium of the National $\mathrm{Hu}-$ man Genome Research Institute and found to have high internal consistency [11]. The interview also included a series of open-end- 
Table 1. Hereditary breast cancer risk based on self-reported family history of breast and ovarian cancer

\begin{tabular}{|c|c|c|c|}
\hline & \multicolumn{2}{|c|}{$\begin{array}{l}\text { Personal history with } \\
\text { breast/ovarian cancer }\end{array}$} & $\begin{array}{l}\text { First-degree relative history with } \\
\text { breast/ovarian cancer }\end{array}$ \\
\hline Low & none & and & none or one late onset \\
\hline Low & late onset & and & none \\
\hline Medium & none & and & $\begin{array}{l}\text { one early onset or two or more late } \\
\text { onsets }\end{array}$ \\
\hline Medium & late onset & and & one affected \\
\hline Medium & early onset & and & none or one late onset \\
\hline High & none & and & $\begin{array}{l}\text { two or more early onset or three or } \\
\text { more affected }\end{array}$ \\
\hline High & early onset & and & one or more early onsets \\
\hline
\end{tabular}

ed questions that asked subjects to relate how they first heard about genetic breast cancer testing, what prompted them to seek testing, whom they consulted while considering whether to test, and what factors contributed to their final decision to test, to delay testing, or not to test. The interviews specifically asked women to describe informed consent sessions or other sessions in which practitioners formally discussed the risks and benefits of BRCA1/2 testing. All interviews were conducted by one of two experienced researchers, one an advanced graduate student in anthropology and the other a recent $\mathrm{PhD}$.

To enhance recall and minimize the effect of post-decisional recall on subject accounts of pre-decisional considerations [12], we followed certain strategies in our interviews. First, to provide a framework for recalling relevant information [14], we asked subjects to provide an overview of the experience of cancer in her life (including the subject's own experience and that of friends and family) and within that context, to describe how she had learned of BRCA1/2 testing. Second, we then asked subjects to recount the evolution of their interest in BRCA testing in a detailed and stepby-step fashion. We were able to use information provided in the first part of the interview to probe any possible inconsistencies appearing in this more detailed account. Third, our interviews were also scheduled at the interviewees' convenience, and from a location of their choice, strategies which increase comfort level and have been shown to increase the validity of self-reports [15].

\section{Coding and Analysis}

Interviews were audio-taped (with the permission of the subject), transcribed, coded, and analyzed. The team employed a technique of Multi-Level Consensus Coding that we developed for a previous interview study to use with NUD*IST qualitative analysis software [16]. The research team developed the coding scheme by first defining initial categories from the text of transcribed interviews. These provisional codes were applied, reviewed, and then revised until the coding scheme was determined to be adequately robust and comprehensive. Each interview was independently coded by two coders, using the final coding scheme, with unresolved discrepancies reconciled by the whole team.

Respondents' hereditary breast cancer risk was assessed based on self-reported individual and family history of breast and ovarian cancers. Applying the criteria listed in table 1 to these self-reports, heredity breast cancer risk was coded as low, medium, and high.
To conduct statistical tests of proportions, we used $\chi^{2}$ tests, and to conduct tests of means, we used t tests.

\section{Results}

\section{Study Population}

From March 1999 through June 2000, 111 women contacted the study's 800 number, leaving a contact phone number for us to call back. Twenty-one were ineligible for the interview, 8 because they were still in the process of deciding whether to be tested or not, and 13 because they mistook our phone number for a genetic testing laboratory. Eleven decided not to participate explaining they were too busy and $11 \mathrm{did}$ not respond to our callback. We conducted 68 telephone interviews, each lasting between 35 and $65 \mathrm{~min}$. All interviews occurred within 6 months of the participants discussing testing with a health care provider, and within 3 months of receiving a test result for those who tested. Due to our indirect sampling and contact method, chosen to preserve the privacy and confidentiality of study participants, we cannot calculate a response rate.

\section{Sociodemographic Characteristics of the Subjects}

Table 2 presents the demographic information of the 68 individuals in the sample. Our sample conforms to that found in many other studies of BRCA1/2 testing in its high rate of college attendance $(53 \%$ had at least a college degree), high incomes (46\% reported household incomes over $\$ 75,000)$, and racial identity $(96 \%$ described themselves as white). Ages ranged from 32 to 76 years, and the average age and modal age were 47 years. Thirtynine participants $(57 \%)$ were affected by breast or ovarian cancer themselves and $52(76 \%)$ had at least one firstdegree relative affected with cancer. 
Table 2. Sociodemographic characteristics and responses to closeended questions

\begin{tabular}{|c|c|c|c|}
\hline Variable & $\begin{array}{l}\text { All subjects } \\
(\mathrm{n}=68) \\
\mathrm{n}(\%)\end{array}$ & $\begin{array}{l}\text { Accepters } \\
(\mathrm{n}=30) \\
\mathrm{n}(\%)\end{array}$ & $\begin{array}{l}\text { Decliners } \\
(\mathrm{n}=38) \\
\mathrm{n}(\%)\end{array}$ \\
\hline \multicolumn{4}{|l|}{ Age } \\
\hline 30-39 years & $17(25)$ & $6(20)$ & $11(29)$ \\
\hline 40-49 years & $27(40)$ & $14(47)$ & $13(34)$ \\
\hline $50-79$ years & $24(35)$ & $10(33)$ & $14(37)$ \\
\hline Income $(\$)$ & 1 missing & & 1 missing \\
\hline$\leq 25,000$ & $8(12)$ & $4(13)$ & $4(11)$ \\
\hline $25,000-75,000$ & $28(41)$ & $12(40)$ & $16(42)$ \\
\hline$>75,000$ & $31(46)$ & $14(47)$ & $17(45)$ \\
\hline \multicolumn{4}{|l|}{ Education } \\
\hline$\leq$ High school & $32(47)$ & $9(30)$ & $23(61)$ \\
\hline$\geq$ College degree & $36(53)$ & $21(70)$ & $15(39)$ \\
\hline \multicolumn{4}{|l|}{ Race/ethnicity ${ }^{\mathrm{a}}$} \\
\hline White & $65(96)$ & & \\
\hline African-American & $2(3)$ & & \\
\hline Hispanic & $1(1)$ & & \\
\hline Religion & 1 missing & & 1 missing \\
\hline None & $7(10)$ & $3(10)$ & $4(11)$ \\
\hline Protestant & $26(38)$ & $9(30)$ & $17(45)$ \\
\hline Catholic & $18(26)$ & $8(27)$ & $10(26)$ \\
\hline Jewish $^{\mathrm{b}}$ & $16(24)$ & $10(33)$ & $6(16)$ \\
\hline \multicolumn{4}{|l|}{ Personal history of } \\
\hline \multicolumn{4}{|c|}{ Hereditary breast cancer risk } \\
\hline Low & $17(25)$ & $6(20)$ & $11(29)$ \\
\hline Medium & $29(43)$ & $14(47)$ & $15(39)$ \\
\hline High & $22(32)$ & $10(33)$ & $12(32)$ \\
\hline Knowledge score & 1 missing & & 1 missing \\
\hline$\leq 6$ correct & $14(21)$ & $1(3)$ & $13(34)$ \\
\hline 7-8 correct & $17(25)$ & $6(20)$ & $11(29)$ \\
\hline$\geq 9$ correct & $36(53)$ & $23(77)$ & $13(34)$ \\
\hline \multicolumn{4}{|l|}{ Practitioners seen (n) } \\
\hline 1 & $26(38)$ & $5(17)$ & $21(55)$ \\
\hline 2 & $28(41)$ & $15(50)$ & $13(34)$ \\
\hline$\geq 3$ & $14(21)$ & $10(33)$ & $4(11)$ \\
\hline
\end{tabular}

\section{Hereditary Breast Cancer Risk}

Based on listed risk criteria, most of the subjects were categorized as being at moderate risk for hereditary breast cancer $(\mathrm{n}=29,43 \%)$, followed by high risk $(\mathrm{n}=22,32 \%)$ and then by low risk $(\mathrm{n}=17,25 \%)$.

\section{Knowledge Score}

The number of correct scores ranged from 2 to 11 . The average score was 8.2 and the modal score was 9. The question missed most often was 'About 1 in 10 women have an altered BRCA gene', with only $35 \%$ of respondents correctly responding 'false'.

\section{Number and Type of Practitioners Seen}

Women named genetic counselors most often as the type of practitioners with whom they had discussed BRCA1/2 testing, followed by oncologists, gynecologists, surgeons, and primary-care physicians. Twenty-six (38\%) subjects reported discussing testing with one practitioner, $28(41 \%)$ reported such discussions with two, and 14 (21\%) reported discussions with three or more practitioners. Women who reported a discussion with only one practitioner typically saw an oncologist.

\section{Testing Decision}

Thirty (44\%) participants were classified as accepting BRCA $1 / 2$ testing and 38 as declining (56\%). The latter group also contained 7 subjects who indicated that they might change their decision and accept testing if certain practical barriers were addressed, such as test cost and the proximity of a testing site. Women who accepted testing compared to those who declined were similar in age, income, cancer status, and hereditary breast cancer risk status. Differences between the two groups occurred in education, with $70 \%$ of accepters reporting college or advanced degrees in contrast to $39 \%$ of decliners ( $\chi^{2}$ test: $p=0.001$ ), and in knowledge scores, which averaged 9 for accepters and 7.1 for decliners ( $t$ test: $p=0.012$ ). Women who accepted testing typically saw two or more practitioners, while those who rejected testing typically saw only one. About twice as many Protestants declined testing as accepted testing; about the same number of Catholics accepted as declined testing, and about twice as many Jewish respondents accepted testing as declined.

\section{Qualitative Analysis of Testing Decision}

Reasons for Inquiring about Testing and Reasons to Test or Not to Test. Statements from the interview about seeking information and making decisions were coded and analyzed to understand the reasons that women considered testing and that some went on to test while others did not (table 3 ). In addition, each interview was reformulated as a one- to two-page narrative account of the subject's personal history with cancer, and the origination and course of her interest in BRCA1/2 testing. Analysis of these data indicated that women considered 
Table 3. Most common reasons given for accepting or declining BRCA1/2 testing

\begin{tabular}{lll}
\hline & \multicolumn{2}{l}{ Respondents } \\
\cline { 2 - 2 } & $\begin{array}{ll}\text { primary } & \text { secondary } \\
\text { reason } & \text { reason }\end{array}$ \\
\hline
\end{tabular}

Reason to test

Better manage cancer risk

Relative's cancer management

Need to know carrier status

$\begin{array}{rl}14 & 1 \\ 11 & 1 \\ 5 & 9\end{array}$

Reason not to test

Would not change management/results too ambiguous

Insurance discrimination

Cost

Lack of family history

No relative to test and accepted BRCA1/2 testing most often as a means of better managing their own cancer risk or that of close relatives. A secondary reason was a personal need to know one's BRCA1/2 status. The major reasons that women gave for deciding against BRCA1/2 testing were the irrelevance of the result for their health management, concerns about insurance discrimination, and cost. Additional factors included practical barriers such as absence of appropriate relatives to test or proximity of test site.

\section{Practitioner Advice about Testing}

Subjects were asked to describe each practitioner encounter they experienced that included a discussion about whether to test, and to recount both basic test information and evaluative statements conveyed by the practitioner.

Table 4. Definitions and numbers of practitioner comments to women seeking BRCA $1 / 2$ testing

\begin{tabular}{|c|c|c|c|}
\hline $\begin{array}{l}\text { Type of } \\
\text { comment }\end{array}$ & $\begin{array}{l}\mathrm{n} \\
(\%)\end{array}$ & Definition & Example \\
\hline $\begin{array}{l}\text { Encouraging } \\
\text { mild }\end{array}$ & $58(32)$ & a single event & $\begin{array}{l}\text { practitioner suggested testing, or provided } \\
\text { patient with a referral }\end{array}$ \\
\hline $\begin{array}{l}\text { Encouraging } \\
\text { strong }\end{array}$ & $30(17)$ & ongoing encouragement & $\begin{array}{l}\text { practitioner described as 'helping me } \\
\text { through the hurdles', or as being 'generally } \\
\text { encouraging' }\end{array}$ \\
\hline Utility + & $19(11)$ & $\begin{array}{l}\text { a comment that relayed some positive } \\
\text { aspect of testing to the patient }\end{array}$ & $\begin{array}{l}\text { 'my practitioner said this would be good } \\
\text { for me psychologically', or that it would } \\
\text { help with planning medical management }\end{array}$ \\
\hline Utility - & $32(18)$ & $\begin{array}{l}\text { a comment that relayed some negative } \\
\text { aspect of testing to the patient }\end{array}$ & $\begin{array}{l}\text { practitioner stating that genetic testing is } \\
\text { not effective, or that the patient's cancer } \\
\text { was probably not genetic }\end{array}$ \\
\hline Insurance + & $7(4)$ & $\begin{array}{l}\text { a comment that relayed some } \\
\text { positive aspect of paying for the test } \\
\text { or insurance coverage }\end{array}$ & $\begin{array}{l}\text { practitioner stating that insurance might/ } \\
\text { will pay }\end{array}$ \\
\hline Insurance - & $15(8)$ & $\begin{array}{l}\text { a comment that relayed some } \\
\text { negative aspect of paying for the test } \\
\text { or insurance coverage }\end{array}$ & $\begin{array}{l}\text { practitioner states that insurance } \\
\text { discrimination exists, or that the test is } \\
\text { very expensive }\end{array}$ \\
\hline Neutral & $18(10)$ & impartial & $\begin{array}{l}\text { participants report that their practitioner } \\
\text { 'provided information', or 'explained the } \\
\text { mechanics of test' }\end{array}$ \\
\hline Total & $179(100)$ & & \\
\hline
\end{tabular}


Subjects' reports of practitioner statements about the advisability or nature of testing were coded into the following categories: (1) generally encouraging (divided into mild and strong statements); (2) utility [statements that addressed the practical limits (negative) or strengths (positive) of the test]; (3) comments about insurance (which are a subset of utility comments) that focus on how insurance issues might facilitate (positive) or impede (negative) testing, and (4) neutral statements, which conveyed test information without an evaluative dimension.

Discouraging statements were in all cases related to either utility or insurance, so there was no category for generally discouraging statements. Table 4 summarizes the criteria used to assign comments to these categories and provides an example of each. One hundred seventynine comments were reported by 68 women covering 120 encounters.

\section{Interest in Practitioner Input into Testing \\ Deliberations}

Subjects were then asked to assess whether they thought that the practitioner statements had influenced their testing considerations and if so, how. We found that subject responses could be categorized as either 'decided already' or 'open'. Two subjects could not be coded in either category, and so were excluded from this analysis. Thus, analysis of this code is conducted on 66 rather than 68 subjects. Comments coded as 'decided already' expressed a clear, preexisting desire to test or not to test, irrespective of practitioner attitude or advice. 'Decided already' characterized the position of $48 \%$ of the subjects $(n=32)$. Statements coded as 'open' implied or stated that women were interested in what practitioners thought about testing and to varying degrees looked to practitioners for help in the decision-making process. Fifty-two percent $(n=34)$ of the subjects made statements coded as 'open'. Table 5 provides sample passages to illustrate these two positions.

Table 6 summarizes how women's decisions to test or not to test correspond to the practitioner comment categories defined in table 4 . Women who accepted testing and those who declined reported receiving roughly the same number of mildly encouraging comments from practitioners. Those who accepted testing, however, reported more strongly encouraging comments and almost four times as many positive utility comments as decliners ( 43 vs. $11 \% ; n=13$ for accepters and $n=4$ for decliners) and fewer negative utility comments than those who declined ( 17 vs. $47 \% ; n=5$ for accepters and $n=18$ for decliners). Positive and negative insurance comments followed a similar pattern, with those accepting testing re-
Table 5. Subject interest in practitioner advice about testing

\section{Sample quotations}

Decided already $(n=32 ; 48 \%)^{\mathrm{a}}$

It wasn't even an issue about whether or not to get tested, I just knew it was something that I had to do.

I mean, I had made up my mind when I went there that day, that I was having it done no matter what was said to me.

It was like once the possibility was there, I decided I knew I wanted to do it, and then I would do it, you know, one way or another.

No, I mean I pretty much went in saying: 'This is what I want, so let's just do it.'

Open $(n=34 ; 52 \%)$

I didn't even know that there was such a genetic test until I was diagnosed. And she (her oncologist) gave me all kind of little information booklets to read and that's where I found in my reading about that and I asked her about it.

I don't know that I, well I might have read about it but I really hadn't. I didn't know that much about it. I knew the sorts of things you can do without HRT $^{\mathrm{b}}$, but I didn't know about the genetic testing really until he (the oncologist) mentioned it and told me where to call and so forth.

I had read about the test, or about the genetic, the gene, the genetic testing, but in what I read, there was no information about possible false positives and things like that. There was no actual cost or, there definitely wasn't anything that told me my insurance would be canceled because it would be considered a preexisting condition if I had it. Umm, so it was after that, it was, I spoke to the doctor after I read the article and started asking all these other questions.

a These figures are based on a sample of 66, not 68 .

${ }^{\mathrm{b}} \mathrm{HRT}=$ Hormone replacement therapy.

ceiving more positive and fewer negative comments than decliners. Accepters reported more neutral comments than decliners.

Seventy-nine percent of women who expressed an openness and interest in practitioners' input to the decision-making process declined testing $(n=27)$. In contrast, of those women who reported contacting practitioners after they had already decided whether they wanted to test, only $31 \%$ declined $(n=10)$. Of these, 5 were among the 7 who cited structural barriers to testing, such as cost, and stated that they would test if they could.

It is possible that subjects who reported having already decided to test independent of practitioner input may differ in terms of cancer history or self-reported cancer risk from those who reported being more open to practitioner 
Table 6. Testing decision and qualitative analysis by accepters and decliners

\begin{tabular}{llcc}
\hline Variable & $\begin{array}{l}\text { Subjects } \\
\mathrm{n}(\%)\end{array}$ & $\begin{array}{l}\text { Accepters } \\
\mathrm{n}(\%)\end{array}$ & $\begin{array}{l}\text { Decliners } \\
\mathrm{n}(\%)\end{array}$ \\
\hline Practitioner comment types reported by each subject & $68(100)$ & $30(100)$ & $38(100)$ \\
Encouraging (mild) & $44(66)$ & $21(70)$ & $23(61)$ \\
Encouraging (strong) & $24(35)$ & $14(47)$ & $10(26)$ \\
Utility + & $17(25)$ & $13(43)$ & $4(11)$ \\
Utility - & $23(33)$ & $5(17)$ & $18(47)$ \\
Insurance + & $7(10)$ & $6(20)$ & $1(3)$ \\
Insurance - & $13(19)$ & $3(10)$ & $10(26)$ \\
Neutral & $15(22)$ & $10(33)$ & $5(13)$ \\
\hline Position toward practitioner role & $66(100)$ & $29(100)$ & $37(100)$ \\
Decided already & $32(48)$ & $22(69)$ & $10(31)$ \\
Open & $34(52)$ & $7(21)$ & $27(79)$ \\
\hline
\end{tabular}

${ }^{1}$ These figures are based on a sample of 66 , not 68 .
Table 7. Cancer status, decided already/open, and testing decision

\begin{tabular}{llll}
\hline Position & $\begin{array}{l}\text { Subjects } \\
\mathrm{n}(\%)\end{array}$ & $\begin{array}{l}\text { Accepters } \\
\mathrm{n}(\%)\end{array}$ & $\begin{array}{l}\text { Decliners } \\
\mathrm{n}(\%)\end{array}$ \\
\hline $\begin{array}{l}\text { Decided already } \\
\text { Cancer + }\end{array}$ & $32(100)$ & $22(100)$ & $10(100)$ \\
Cancer - & $22(69)$ & $15(68)$ & $7(32)$ \\
Open & $10(31)$ & $7(70)$ & $3(30)$ \\
Cancer + & $34(100)$ & $7(21)$ & $27(79)$ \\
Cancer - & $17(50)$ & $3(18)$ & $14(82)$ \\
\hline
\end{tabular}

These figures are based on a sample of 66 , not 68 .

influence. Table 7 presents the similarities and differences of the two groups on these dimensions.

Table 7 suggests that women who have had breast or ovarian cancer are more likely to say that they had decided whether to test before attending genetic counseling or going through informed consent. Fifty-nine percent $(n=39)$ of the 66 subjects who could be coded to decided already or open had had either breast or ovarian cancer. Considering only those categorized as 'decided already', this figure increases to $69 \%(\mathrm{n}=22)$ and for those categorized as 'open', it drops to $50 \%(\mathrm{n}=17 ; \mathrm{p}=0.12)$. However, regardless of the cancer status, those who had 'decided already' are more likely to test than others; $69 \%$ of the former ('decided already') test compared to $21 \%$ of the latter ('open'; $p<0.001$ ). It is also of interest that the median score on the knowledge test was 6 for the 'open ones' and over 10 for those who had 'decided already'.

\section{Discussion}

This study examined a national sample of women who considered BRCA1/2 testing in a clinical setting and came to a determination to test, or not to test. The strength of the study lies in the fact that the subjects were women who actually had gone through the process of considering testing for themselves rather than considering the question as part of a research protocol. It revealed that many women report deciding whether to undergo testing before discussing it with a practitioner or counselor. This pattern of decision-making might be obscured or not detectable in hypothetical vignette studies or among subjects enrolled in research trials on genetic testing. The latter is the case because women who know they want to test also typically want test results, which are often unavailable in research trials.

Of the subjects interviewed, slightly less than half had accepted testing at the time of our interview and slightly more than half had rejected the option or delayed their decision. The rate of decliners is higher in this study than in previous studies of women considering genetic testing in the context of research protocols [7-9]. As the design of this study targeted women who were considering testing in real clinical settings, the implication may be that more women who consider BRCA1/2 genetic testing decline the option than was previously recognized. However, because the subjects in this study were a small group of self-selected volunteers, inferences from such comparisons are limited.

Qualitative analysis of the interview transcripts demonstrates that women engaged the test decision-making 
process in a variety of ways. Some reported a path similar to that presumed by the ASCO guidelines [1] in that they reported relying on information provided by one or more practitioners during their testing deliberations. The majority of these women did not test. In contrast, others described a decision-making process that they claimed occurred prior to interactions with practitioners and that was characterized by a strong commitment to be tested. Regardless of cancer status, the majority of these women did test. The existence of this group raises questions about the premise underlying current reliance on informed consent or counseling to screen potential testers and protect against the test's 'potential medical, psychological, and other personal risks' [1]. The fact that counseling was reported as less influential with this group does not mean that counseling is unnecessary. Rather it suggests that with enough perseverance women can gain approval for testing with less attention to medical appropriateness than policies seem to presume. The tendency of this group to score high on knowledge tests suggests that self-education facilitates these goals.

Those who accepted testing reported more positive utility and positive insurance comments from practitioners than those who declined. This difference may in part be accounted for by the fact that they were also more likely to have seen multiple practitioners and had to eventually find one who approved their decision to test. Hereditary breast cancer risk was not a major factor in differentiating the two groups. While those with low hereditary breast cancer risk were slightly less likely to test, there was no significant difference in the moderate- and high-risk groups between acceptors and decliners. It is interesting to note, considering the research emphasis on psychological implications to genetic testing [17-19], that neither accepters nor decliners cited psychological concerns as primary or secondary influences on testing decisions.

The implications of these findings for practitioners, genetic counselors, and those involved in the genetic testing enterprise are worth noting. Many women enter the clinic having already made a choice about testing, and these women are often well informed about the pros and cons, as well as the factual basis, of genetic testing. Counseling might not be as influential with these women. The group of women in our study who had 'decided already' may be similar to those found in another study of women in a Breast and Ovarian Cancer Risk Evaluation Program who did not want to know whether their doctors thought they should have BRCA1/2 testing [20].
In addition, the single most important reason to test cited by the women in our sample - both those who accepted testing and those who declined - is the implication of testing for cancer management. Practitioners discussing genetic testing should not slight a full discussion of management options. The ASCO 2003 revised policy statement on genetic testing confirms this point [21]. This statement highlights the role of genetic counselors, but our research highlights its relevance for all health care practitioners discussing BRCA testing with patients.

Another important finding is the seriousness with which women took the insurance implications of testing in their decision-making process. This finding is consistent with others in the literature suggesting that insurance implications are an important consideration in deciding to accept or decline genetic testing [22]. Even casual comments by practitioners about insurance risks at times were instrumental in women's decision to decline testing. Practitioners should be careful in their discussion of insurance with women considering testing, and give an accurate account of insurance implications.

Finally, we note the limitations of the sample. The subject pool was self-selected, and so these data might not generalize to the actual population of women considering testing. However, the subjects do represent a national rather than a regional sample, are drawn from diverse clinical settings and a variety of practitioner types, and are demographically similar to other breast cancer samples in the literature. Also, the data derive from retrospective self-report and are vulnerable to the biases created by revisions and gaps inherent in recall. However, we structured our interview to limit the influence of post-decisional recall on explanations of pre-decisional considerations by asking subjects first to provide an overall framework for recollection and then to provide an account that focused on the detail of each practitioner interaction rather than on the decision itself. Further, analysis for novel codes such as 'decided already' and 'open' was not based on a solitary yes/no question, but on a series of questions and an analysis of the narrative accounts created for each interview.

\section{Conclusion}

Women decide to accept or decline BRCA1/2 genetic testing for a variety of reasons. An understanding of the dynamics of such decision-making is important for the proper counseling of women both before and after testing. While research based on hypothetical vignettes or with 
subjects in research settings provide valuable insights, women who are engaged in making real decisions in clinical settings may respond in ways that are undetectable using the other research strategies. More research on the dynamics of genetic test decision-making is imperative as more tests become available and the implications of testing for medical management become more complex.

\section{Acknowledgment}

This research was funded in part by a grant from the NIH/NHGRI R01 HG01576.

\section{References}

$>1$ Statement of the American Society of Clinical Oncology: genetic testing for cancer susceptibility, adopted on February 20, 1996. J Clin Oncol 1996;14:1730-1736.

$>2$ Armstrong K, Weber B, Ubel PA, Guerra C, Schwartz JS: Interest in BRCA $1 / 2$ testing in a primary care population. Prev Med 2002;34: 590-595.

-3 Audrain J, Rimer B, Cella D, Garber J, Peshkin BN, Ellis J, Schildkraut J, Stefanek M, Vogel V, Lerman C: Genetic counseling and testing for breast-ovarian cancer susceptibility: what do women want? J Clin Oncol 1998;16: 133-138.

$\checkmark 4$ Bernhardt B, Geller G, Doksum T, Metz SA: Evaluation of nurses and genetic counselors as providers of education about breast cancer susceptibility testing. Oncol Nurs Forum 2000;27: 33-39.

$\checkmark 5$ Gwyn K, Vernon S, Conoley P: Intention to pursue genetic testing for breast cancer among women due for screening mammography. Cancer Epidemiol Biomarkers Prev 2003;12:96102.

-6 Thompson H, Valdimarsdottir HB, DuteauBuck C, Guevarra J, Bovbjerg DH, RichmondAvellaneda C, Amarel D, Godfrey D, Brown K, Offit K: Psychosocial predictors of BRCA counseling and testing decisions among urban African-American women. Cancer Epidemiol Biomarkers Prev 2002;11:1579-1585.

-7 Armstrong K, Calzone K, Stopfer J, Fitzgerald G, Coyne J, Weber B: Factors associated with decisions about clinical BRCA $1 / 2$ testing. Cancer Epidemiol Biomarkers Prev 2000;9: 1251-1254.
$>8$ Biesecker B, Ishibe N, Hadley DW, Giambarresi TR, Kase RG, Lerman C, Struewing JP: Psychosocial factors predicting BRCA1/ BRCA2 testing decisions in members of hereditary breast and ovarian cancer families. Am J Med Genet 2000;93:257-263.

$>9$ Botkin J, Smith KR, Croyle RT, Baty BJ, Wylie JE, Dutson D, Chan A, Hamann HA, Lerman C, McDonald J, Venne V, Ward JH, Lyon E: Genetic testing for a BRCA 1 mutation: prophylactic surgery and screening behavior in women 2 years post testing. Am J Med Genet A 2003;118:201-209.

10 Armstrong K, Weiner J, Weber B, Asch DA: Early adoption of BRCA $1 / 2$ testing: who and why. Genet Med 2003;5:92-98.

11 Lerman C, Narod S, Schulman K, Hughes C, Gomez-Caminero A, Bonney G, Gold K, Trock B, Main D, Lynch J, Fulmore C, Snyder C, Lemon SJ, Conway T, Tonin P, Lenoir G, Lynch H: BRCA 1 testing in families with hereditary breast-ovarian cancer: a prospective study of patient decision making and outcomes. JAMA 1996;275:1885-1892.

12 Bernard H, Kilworth P,Kronenfeld D, Sailer L: The problem of informant accuracy: the validity of retrospective data. Ann Rev Anthropol 1984; 13:495-517.

13 Cho M, Sankar P, Wolpe PR, Godmilow L: Commercialization of BRCA $1 / 2$ testing: practitioner awareness and use of a new genetic test. Am J Med Genet 1999;83:157-163.

14 Berney L, Blane D: Collecting retrospective data: accuracy of recall after 50 years judged against historical records. Soc Sci Med 1997; 45:1519-1525.

$>15$ Crisanti A, Laygo R, Junginger J: A review of the validity of self-reported arrests among persons with mental illness. Curr Opin Psychiatry 2003;16:565-569.
16 Jenkins G, Merz J, Sankar P: A qualitative study of women's views on medical confidentiality. J Med Ethics 2005;31:499-504

17 Andrews L, Meiser B, Apicella C, Tucker K: Psychological impact of genetic testing for breast cancer susceptibility in women of Ashkenazi Jewish background: a prospective study. Genet Test 2004;8:240-247.

18 Halbert CH, Schwartz MD, Wenzel L, Narod S, Peshkin BN, Cella D, Lerman C: Predictors of cognitive appraisals following genetic testing for BRCA1 and BRCA2 mutations. $\mathrm{J}$ Behav Med 2004;27:373-392.

19 McInerney-Leo A, Biesecker BB, Hadley DW, Kase RG, Giambarresi TR, Johnson E, Lerman C, Struewing JP: BRCA1/2 testing in hereditary breast and ovarian cancer families: Effectiveness of problem-solving training as a counseling intervention. Am J Med Genet A 2004; 130:221-227.

20 Armstrong K, Stopfer J, Calzone K, Fitzgerald G, Coyne J, Weber B: What does my doctor think? Preferences for knowing the doctor's opinion among women considering clinical testing for BRCA $1 / 2$ mutations. Genet Test 2002;6:115-118.

21 American Society of Clinical Oncology: Policy statement update: genetic testing for cancer susceptibility. J Clin Oncol 2003;21:23972406.

22 Peterson E, Milliron KJ, Lewis KE, Goold SD, Merajver SD: Health insurance and discrimination concerns and BRCA $1 / 2$ testing in a clinic population. Cancer Epidemiol Biomarkers Prev 2002;11:79-87. 